\title{
A review of the association between congestive heart failure and cognitive impairment.
}

\author{
Michael B. Cohen \\ Thomas Jefferson University \\ Paul J. Mather \\ Thomas Jefferson University
}

Follow this and additional works at: https://jdc.jefferson.edu/cardiologyfp

Part of the Cardiology Commons

Let us know how access to this document benefits you

\section{Recommended Citation}

Cohen, Michael B. and Mather, Paul J., "A review of the association between congestive heart failure and cognitive impairment." (2007). Division of Cardiology Faculty Papers. Paper 2.

https://jdc.jefferson.edu/cardiologyfp/2

This Article is brought to you for free and open access by the Jefferson Digital Commons. The Jefferson Digital Commons is a service of Thomas Jefferson University's Center for Teaching and Learning (CTL). The Commons is a showcase for Jefferson books and journals, peer-reviewed scholarly publications, unique historical collections from the University archives, and teaching tools. The Jefferson Digital Commons allows researchers and interested readers anywhere in the world to learn about and keep up to date with Jefferson scholarship. This article has been accepted for inclusion in Division of Cardiology Faculty Papers by an authorized administrator of the Jefferson Digital Commons. For more information, please contact: JeffersonDigitalCommons@jefferson.edu. 
As submitted to The American journal of geriatric cardiology and later published as:

"A review of the association between congestive heart failure and cognitive impairment"

The American journal of geriatric cardiology

Volume 16, Issue 3, May 2007, Pages 171-174

DOI: $10.1111 / j .1076-7460.2007 .06563 . x$

A Review of the Association between Congestive Heart Failure and

Cognitive Impairment

Paul J. Mather M.D., and Michael B. Cohen M.D.

From: Jefferson Medical College of Thomas Jefferson University, Philadelphia, PA Address for correspondence:

Paul J. Mather, MD

Jefferson Heart Institute

925 Chestnut Street, Mezzanine

Philadelphia, PA 19107

Tel: 215-955-2050

Fax: 215-503-0052

Email: paul.mather@jefferson.edu 


\section{Introduction:}

Heart failure is a set of complex clinical syndromes characterized by impaired cardiac, vascular, and renal function, diminished exercise tolerance, a high incidence of ventricular arrhythmias, and a shortened life expectancy. Heart failure is the only cardiovascular disease diagnosis increasing in prevalence in the United States. Every year 500,000 patients are diagnosed with heart failure, and currently approximately 5,000,000 Americans are afflicted with this condition. ${ }^{1}$. Heart failure is the most common reason for admission to an American hospital among adults over the age of 65, with a readmission rate of $44 \%$ within 6 months. ${ }^{2}$

Congestive Heart Failure (CHF), the terminal manifestation of various heart diseases, represents the most frequent cause of morbidity and mortality in patients aged 65 years and older. Cognitive impairment (CI) is very prevalent in the aging and several clinical trials have demonstrated a high association between cardiovascular diseases, particularly $\mathrm{CHF}$, and cognitive deterioration. The underlying mechanism for cognitive impairment is still unclear but appears to be related to impaired cerebral hypoperfusion and flow regulation. There appears to be selective cognitive impairment of verbal memory and attention domains.

\section{Cognitive dysfunction and heart failure:}

$\mathrm{CHF}$ has been proposed as a possible cause of cognitive dysfunction since 1977. Initial studies demonstrated that hypotension and congestive heart failure are risk factors for 
dementia in elderly people. Roman (1987) reported that reduction of cerebral blood flow may precede cognitive deterioration associated with typical, diffuse, cerebral periventricular white matter changes (leucoaraiosis). ${ }^{3}$ These alterations appeared to be related with low cardiac output. Acanforo et al. (1993) confirmed that luecoaraiosis is significantly related to age, congestive heart failure, and hypotension (systolic blood pressure $<130 \mathrm{mmHg}) .^{4}$ Furthermore, rather than studying the association of dementia in relation to cardiovascular diseases, Gorkin et al., introduced neuropsychological tests to evaluate the quality of life in patients with left ventricular dysfunction (SOLVD study). ${ }^{5}$ The authors concluded that patients with NYHA I obtained better results on tests assessing sustained attention than patients with NYHA Class II and III.

These earlier studies established an association between heart failure and cognitive deterioration but clinical trials detailing this association were needed. The CHF Italian Study I, a multicenter study on hospitalized elderly CHF patients, included a brief screening of cognitive abilities. The Mini Mental State Examination (MMSE) was used for the evaluation of cognitive function. The presence of congestive heart failure was associated with a significant decrease of MMSE scores: mean MMSE score after statistical adjustment for confounding variables (age, BP, previous CVA's and education) was about one point lower in patients with congestive heart failure in contrast to elderly patients affected by heart disease but without congestive heart failure. ${ }^{4}$ This has been duplicated in cognitively impaired patients with end-stage heart failure awaiting transplantation. There is a significant improvement in cognitive function, measured with the MMSE, after undergoing cardiac transplantation. ${ }^{6}$ 
The prevalence of CHF in cognitively impaired subjects is high and the risk of CI is 1.96fold greater in subjects with $\mathrm{CHF}^{7}$ This was examined in a cross-sectional study of 1072 subjects aged 65 years and older in Southern Italy. A MMSE score $<24$ indicated cognitive impairment. The prevalence of CHF in subjects with an MMSE score of $<24$ and $>24$ was $20.2 \%$ and $4.6 \%$, respectively $(\mathrm{p}<.001) .{ }^{7}$ Logistic regression analysis showed that CHF was independently associated with CI by age, sex, educational level, GDS, diabetes, HTN, alcohol consumption, smoking, atrial fibrillation, HR, and systolic and diastolic BP. ${ }^{3}$ Moreover, systolic BP correlated negatively with NYHA classes only in subjects with cognitive impairment, whereas HR increase correlated positively with NYHA classes only in subjects without cognitive impairment. ${ }^{7}$ This analysis suggests that systolic BP reduction and the lack of HR increase, related to NYHA classes, might characterize cognitively impaired subjects with CHF. Since there was no difference in CHF therapy between subjects with MMSE $<24$ and those with MMSE $>24$, the lack of HR increase could not be explained by beta blocker therapy.

Verbal memory and attention appear to be the domains of cognitive impairment most affected in CHF patients. The severity of cognitive impairment parallels that of CHF as expressed by NYHA class. Incalzi et al. further delineated the effect of CHF on verbal memory, specifically primary (short term memory) and secondary (long term) memory. ${ }^{8}$ In addition, they analyzed the mechanisms of memory impairment in different stages of CHF. Performance on some verbal memory indexes (Recency, Rey's immediate and delayed recall, Learning efficiency) progressively decreased from NYHA II to IV. ${ }^{8}$ Rate 
of forgetting was uniformly high across NYHA II-IV which suggests that memory dysfunction complicating CHF has some specific features. ${ }^{8}$ The prevalent impairment of the Recency index, which assesses primary memory, suggests that CHF affects mainly the component of memory which declines less with aging. ${ }^{8}$ Further, the MMSE actually has poor sensitivity and specificity versus primary or secondary memory dysfunction. ${ }^{5}$ Therefore, a deficit of both primary and secondary memory is relatively common in CHF but cannot accurately be recognized by a screening neuropsychological test. ${ }^{8}$

\section{Mechanism of cognitive dysfunction and heart failure:}

Cerebral hypoperfusion may be the common pathophysiologic mechanism by which CHF patients develop dementia. Since blood pressure is usually adequately maintained in patients with LV dysfunction, low cardiac output, as opposed to systemic hypotension, is likely the primary etiology of reduced cerebral blood flow. ${ }^{9}$

In addition, cerebral reactivity is impaired in patients with cardiac failure and a decline in cardiac function correlates with a reduction in cerebrovascular reactivity. Georgiadis et al. measured end-tidal $\mathrm{CO} 2$ values during normocapnia and hypercapnia induction as well as peak $\mathrm{CO} 2$ values and corresponding mean blood flow velocities in the right and left middle cerebral arteries. ${ }^{10}$ Cerebrovascular reactivity (CR) was calculated using these variables. CR was significantly higher in controls as compared to all patient groups, and in NYHA II and III as compared to NYHA IV patients; there was no statistical difference between class II and III patients ${ }^{10}$ (Figure 1). In theory, a decline in cardiac output may lead to partial recruitment of cerebrovascular reactive dilatory capacity in 
patients with chronic heart failure. This decline in cerebrovascular reserve capacity could be responsible for the cognitive dysfunction that has been observed. ${ }^{10}$

\section{Cerebrovascular reactivity in heart failure patients and normal controls (figure 1)}

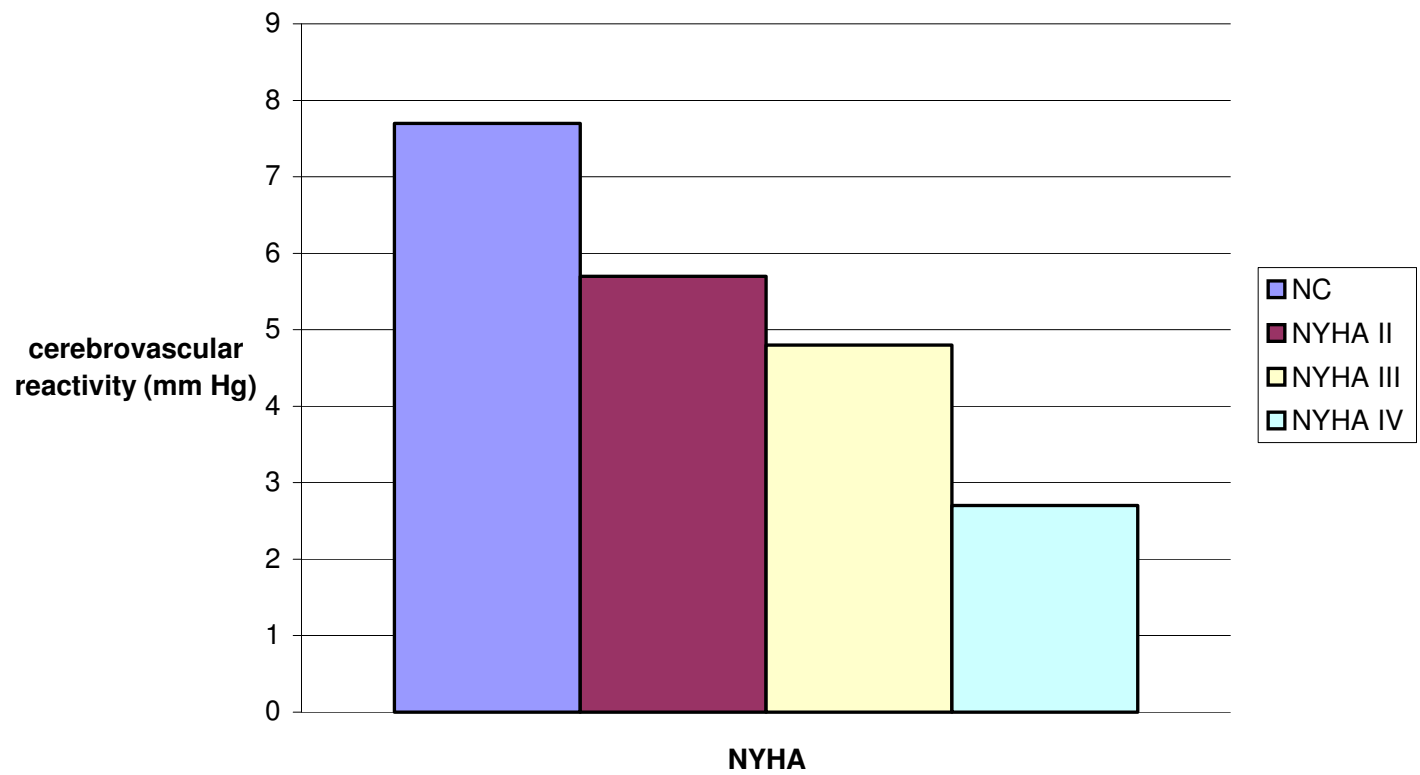

Cerebral metabolic abnormalities have also been investigated as a potential marker of disease severity in CHF, but their prognostic significance remains unclear. Lee et al. investigated the prognostic value of cerebral metabolic abnormalities in 130 patients being evaluated for cardiac transplantation. ${ }^{11}$ Occipital $\mathrm{N}$-acetylaspartate was shown to be an independent predictor of death. ${ }^{11}$ These results suggest that an integrated examination of both perfusion and metabolite concentrations in heart failure patients with cognitive dysfunction may be informative. This may provide insight into a final common biochemical pathway linking cognitive decline and heart failure progression.

Relationship between frailty, $\mathrm{CHF}$, and mortality: 
Cognitive impairment is just one aspect of frailty, a novel concept that is not yet well defined in the literature. Frailty is a complex entity that encompasses a range of clinical conditions such as limited mobility with a predilection to falls, polypharmacy, comorbidity, low social status, nutritional impairment and cognitive impairment. ${ }^{12}$ Previous methods to grade frailty have focused only on the physical domain. A grading system was developed that is more consistent with the complexity of frailty. The authors used The Frailty Staging System (FSS) as an index of severity of functional impairment. ${ }^{12}$ The FSS integrates seven core domains of functioning: disability, mobility, cognitive function, visual function, hearing function, urinary continence and social support. Subjects were then stratified into three classes of frailty. ${ }^{12}$ In subjects with CHF stratified into classes of frailty, there was a statistically significant increase in age, comorbidity and disability and a decrease in MMSE score. ${ }^{12}$ Significantly, KaplanMeier analysis shows that at 9 years the probability of survival progressively decreased with frailty, increasing from $45.5 \%$ to 0 in subjects with $\mathrm{CHF}$ and from $62.8 \%$ to $25.9 \%$ in those without CHF. ${ }^{9}$ Median survival (in months) for patients with CHF in frailty classes 1, 2 and 3 was 101.2, 72.0 and 60.0, respectively. (Figure 2). Thus, frailty represents a new variable that independently predicts mortality in elderly CHF patients. ${ }^{12}$ 
Frailty and median survival (figure 2)

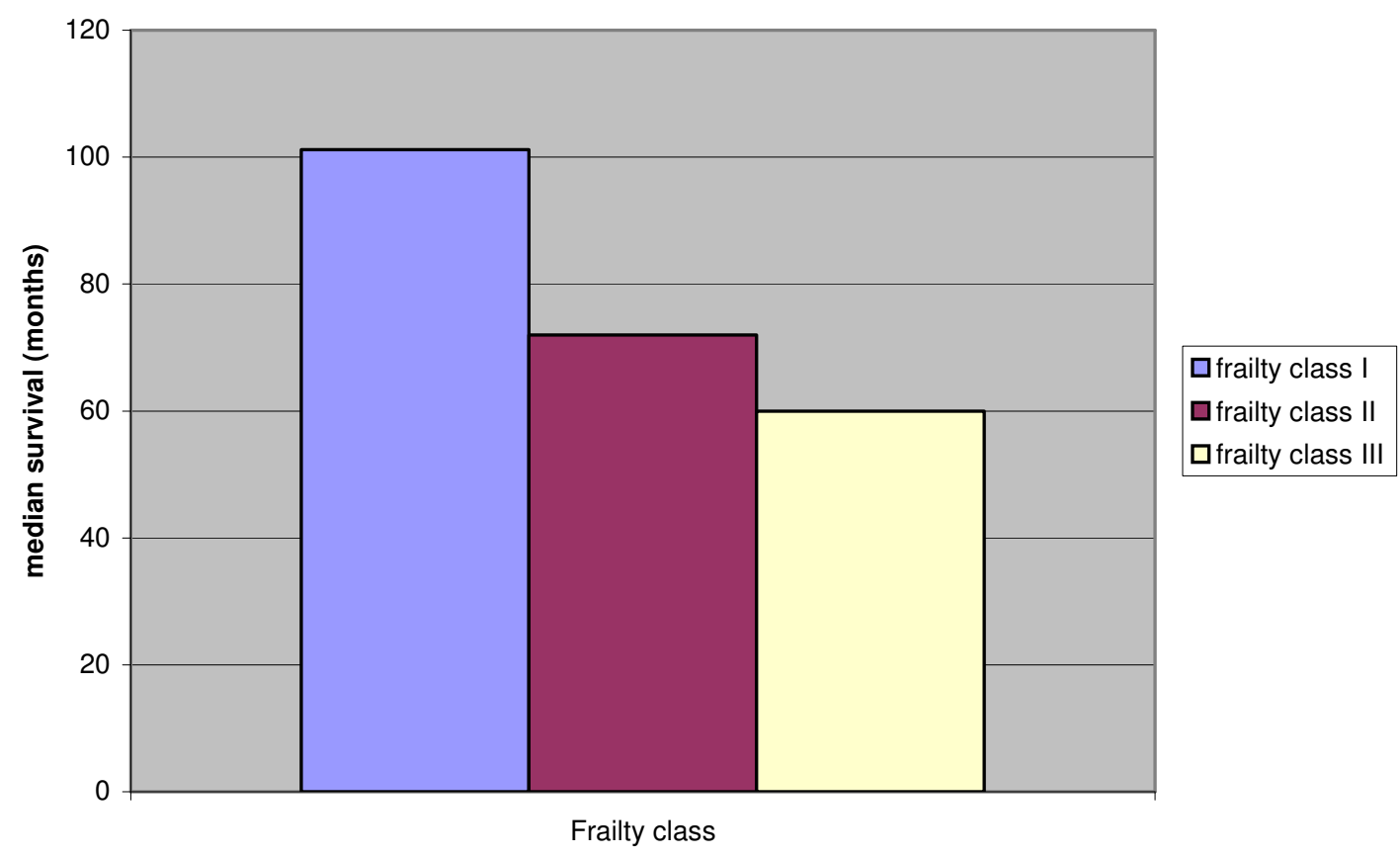

\section{Conclusions:}

As heart failure continues to be major and growing public health problem in the United States with a significant morbidity and mortality the complex nature of this clinical syndrome requires a multidisciplinary approach to, both deal with the devastating consequences of the disease process, but also to create an environment for both physical and mental rehabilitation. Cognitive impairment appears to be a relatively common and predictable effect of CHF. It could contribute with social and behavioral problems that decrease the compliance of CHF patients to prescribed therapy and, as a consequence, increase the rate of hospital readmissions. The validity of the MMSE, once though to be 
the ideal test for assessing cognitive impairment, needs to be readdressed. Nonetheless, further investigation should clarify whether memory-enhancing protocols might improve the compliance of CHF patients. The efficacy of assessing and treating low output states by measuring cerebral reactivity and cerebral metabolites across the spectrum of heart failure patients also needs to be elucidated in larger clinical trials. Finally, further investigation into the concept of frailty and the relationship to congestive heart failure and mortality is necessary in larger CHF cohort studies. Further studies are also needed to elucidate the underlying mechanism(s) of cognitive impairment and whether memory impairment can be prevented or slowed by properly designed training programs thereby improving the quality of life of the patient.

\footnotetext{
${ }^{1}$ American Heart Association. Heart Disease and Stroke Statistics: 2004 Update. Dallas, TX: American Heart Association;2004.

${ }^{2}$ Berry C, Murdoch DR, McMurray JJ. Economics of chronic heart failure. Eur J Heart Fail 2001; 3: 28391.

${ }^{3}$ Rengo F, Acanfora D, Trojano L, Scognamiglio P, Ciaburri F, Ceriello A, Bollella OF, Lanzillo T, Papa A. Congestive heart failure and cognitive impairment in the elderly. Archives of Gerontology and Geriatrics 1995; 20: 63-68.

${ }^{4}$ Acanforo D, Trojano L, Iannuzzi GL, Furgi G, Picone C, Rengo C, Abete P, Rengo F, CHF Italian Study Investigators. The brain in congestive heart failure. Archives of Gerontology and Geriatrics 1996; 23: 247-256.

${ }^{5}$ Gorkin L, Norvell NK, Rosen RC, Charles E, Shumaker SA, McIntyre KM, Capone RJ, Kostis J, Niaura R, Woods P, et al.Am J Cardiol. 1993 May 1;71(12):1069-73
} 
${ }^{66}$ Cacciatore F, Abete P, Ferrara N, Calabrese C, Napoli C, Maggi S, Varricchio M, Rengo F, Osservatorio Geriatrico Compano Study Group. Congestive heart failure and cognitive impairment in an older population. Journal of the American Geriatric Society 1998; 46: 1343-1348.

${ }^{7}$ Tojano L, Incalzi RA, Acaforo D, Picone C, Mecocci P, Rengo F, CHF Italian Study Investigators. Cognitive Impairment: a key feature of congestive heart failure in the elderly. Journal of Neurology 2003; 250: $1456-1463$.

${ }^{8}$ Incalzi RA, Trojano L, Acanforo D, Crisci C, Tarantino F, Abete P, Rengo F, CHF Italian Study Investigators. Verbal memory impairment in congestive heart failure. Journal of Clinical and Experimental neuropsychology 2003; 25: 14-23.

9 Pullicino PM, Hart J, Cognitive Impairment in congestive heart failure(editorial). Neurology 2001; 57: 1945-1946.

${ }^{10}$ Georgiadis D, Sievert M, Cencetti S, Uhlmann F, Krivokuca M, Zierz S, Werdan K. Cerebrovascular reactivity is impaired in patients with cardiac failure. European Heart Journal 2000; 21: 407-413.

${ }^{11}$ Lee CW, Lee JH, Lim TH, Yang HS, Hong MK, Song JK, Park SW, Park SJ, Kim JJ. Prognostic significance of cerebral metabolic abnormalities in patients with congestive heart failure. Circulation 2001; 103: 2784-2787.

${ }^{12}$ Cacciatore F, Abete P, Mazzella F, Viati L, Della Morte D, D’Ambrosio D, Gargiulo G, Testa G, De Santis D, Galizia G, Ferrara N, Rengo F. Frailty predicts long-term mortality in elderly subjects with chronic heart failure. European Journal of Clinical Investigation 2005; 35: 723-730. 